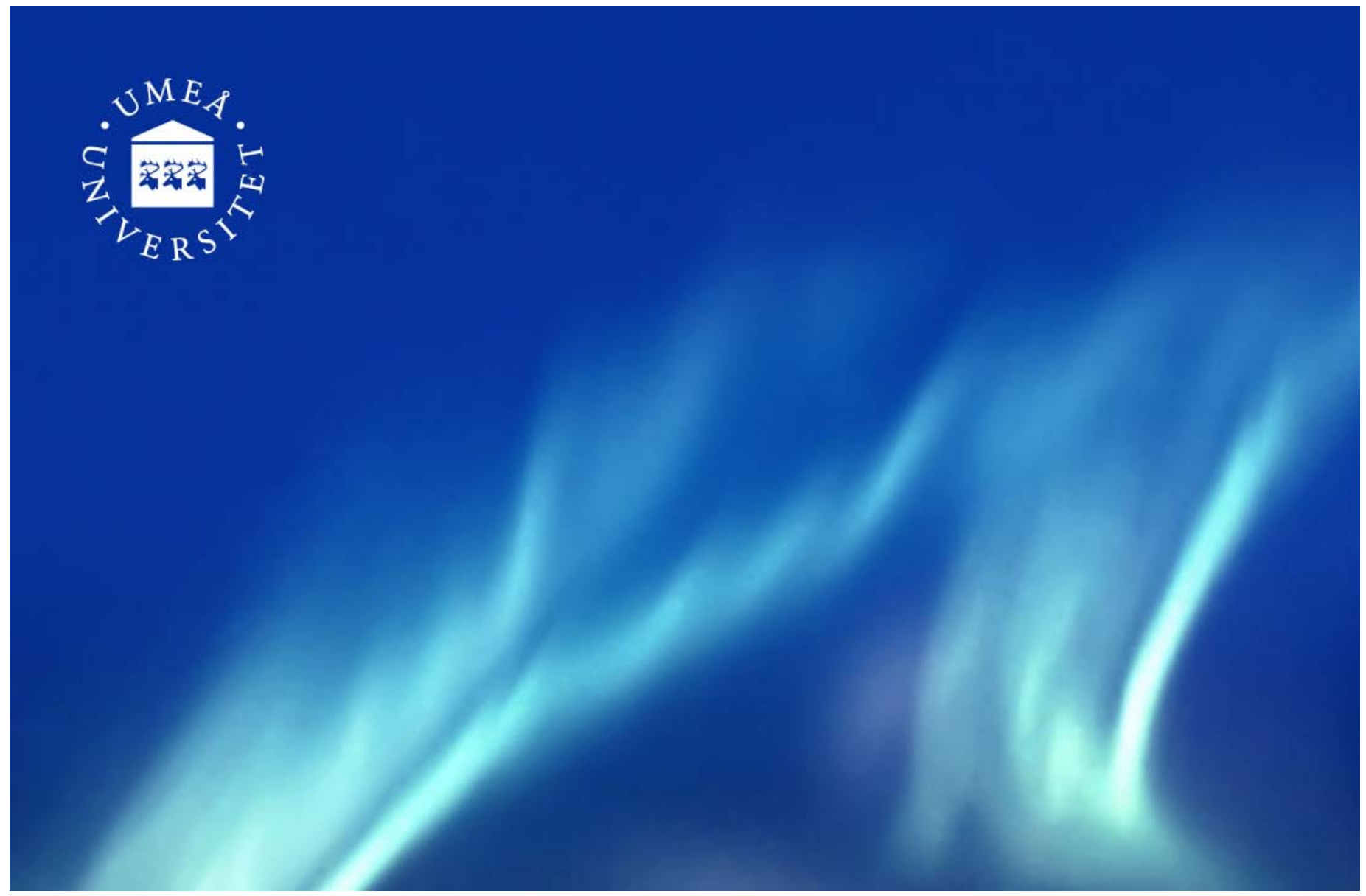

DiVA - Digitala Vetenskapliga Arkivet http://umu.diva-portal.org

This is an author produced version of a paper published in Technology, Pedagogy and Education

This paper has been peer-reviewed but does not include the final publisher proof-corrections or journal pagination.

Citation for the published paper:

\title{
Carina Granberg
}

Implementing digital individual development planning in teacher education: the challenges of communication in relation to the development of ICT-supported methods

Technology, Pedagogy and Education, 2009, Vol. 18, Issue: 2, 123-135

DOI: $10.1080 / 14759390902992543$

Access to the published version may require subscription. Published with permission from:

Routledge, Taylor \& Francis Group 


\title{
Implementing digital individual development planning in teacher education: The challenges of communication in relation to the development of ICT-supported methods
}

\author{
Carina Granberg \\ carina.granberg@educ.umu \\ Department of Interactive Media and Learning \\ Umeå University, Teacher Education, Sweden
}

\begin{abstract}
This paper presents a study of the experiences of a group of teacher educators during the 2006-2007 academic year, when they participated in a project to try out and implement digital individual development planning which in Swedish is digital 'Individuella Utvecklings-Planer (IUP) in a Teacher Education Faculty at a Swedish university. The project group consisted of seven female teacher educators and three colleague mentors. They shared their experiences of the project and how they viewed their roles in the implementation process through individual narrative interviews. In order to illuminate how the attributes of digital IUP were perceived and how these attributes were communicated within the Faculty, the data were analysed in light of Rogers' (2003) diffusion of innovation. Furthermore, concepts of symbolic capital from Bourdieu (1984) were used in analysing the teacher educators' positions as change agents. The article presents a discussion of the circumstances in which digital IUP promotes reflective dialogue. Furthermore, it illuminates the change process and the participants as change agents from a power relation perspective, highlighting communication and shared pedagogical visions.
\end{abstract}

Keywords: teacher education; ICT; individual development planning; diffusion of innovation

\section{Introduction}

The question "What did you learn in school today?" may inspire the response "Nothing", which, though not necessarily the case, implies that the learner may not have reflected on the knowledge gained that day. To focus on learning processes, schools have recently begun using approaches such as portfolios and development planning. As information and communications technology (ICT) use has increased, various ICT applications designed to support these approaches have proven useful (Conole \& Dyke, 2004). Such developments have influenced teacher education, though implementing new technology and assessment methods in this context can be somewhat challenging processes (Hall \& Hord, 2001). This paper analyses the experiences of ten Swedish teacher educators in introducing digital IUP and how these experiences, and their particular circumstances as change agents, interact with the process of change. The seven female teacher educators will be referred to as teachers, the three colleague mentors as mentors and the student teachers as students. 


\section{Background}

\section{Process-based learning}

The understanding and practice of methods such as development planning, portfolios, and process diaries vary widely. They all aim, however, to emphasise the process of learning. Formative assessment, whereby teachers provide continuous feedback throughout the course, shifts some emphasis from the final product to the learning process (Black \& William, 1998). Ideas such as these, that pay greater attention to students' learning activities, will, in this article, be referred to collectively as process-based learning.

There is a movement in higher education across Europe towards the use of development planning (Clegg \& Bradley, 2006). For example, a national resolution in the United Kingdom requires that all students in higher education be offered personal development planning (PDP) (QAA, 2001). The guidelines state that PDP aims to help students reflect on and take responsibility for their own learning, guiding them with teacher feedback on their learning process. However, PDP is not intended for summative assessments (ibid.).

In parts of Europe, the United States of America and Australia, there is a tradition in teacher education of using various kinds of portfolios (Dysthe \& Engelsen, 2004; Strudler \& Wetzel, 2005; Woodward \& Nanlohy, 2004). Other, similar approaches through which students document and reflect on their own learning include reflective journals (Clarke, 2004) and process diaries (Bergström \& Granberg, 2007).

Process-based learning finds different expressions in different contexts. However, there are usually no general requirements to use ICT to support these concepts. PDP guidelines do not, for example, present ICT as essential (QAA, 2001.). There is, however, ongoing discussion as to how ICT may enhance learning (Strudler \& Wetzel, 2005.; Woodward \& Nanlohy, 2004). Notably, the European Commission has taken action regarding ICT in learning, by highlighting digital competence as one of eight key competences for education (The European Parliament and Council of the European Union, 2006).

\section{ICT to support process-based learning}

The role of ICT in learning environments has evolved over time: from once having been dominated by a behaviouristic perspective, it is now influenced by constructivist and sociocultural perspectives (Dysthe, 2002; Koschmann, 1996).

In that role, independent of time and location, ICT makes documentation available and provides for both synchronic and asynchronic communication in the study group. Thus, ICT can support collaboration and dialogue, and through these social meetings, knowledge can be constructed (Dysthe, 2002). Methods focusing on the learning process supported by ICT allow students to work independently and observe their own learning, letting teachers give individual feedback (Webb, 2005). Social meetings and collaboration in digital environments will not occur without intervention, however. Teachers and students must be present in the digital environment, and ICT must have social affordances to make this presence visible in order to promote social interaction (Kreijns \& Kirschner, 2001; Richardsson \& Swan, 2003).

\section{Implementing ICT and process-based learning}

Introducing and implementing new ideas or technology in learning organisations is a complex process in which a lack of knowledge, opposition to top-down decisions, and weak leadership are common obstacles (Finley \& Hartman, 2004; Kirschner \& Selinger, 2003; McCarney, 2004). Implementing PDP in the UK has proven to be no exception, as Clegg and Bradley (2006) point out, indicating that both students and teachers find reflection - the core of the PDP concept - to be difficult. This, together with scepticism towards central government decisions and prior experience of unsuccessful implementation, is likely to slow the process of change. Similar conditions exist in Swedish universities. An inquiry into teacher education, 
which constitutes the context of this paper, found that ICT is seldom used to support learning in campus courses. The teachers described the obstacles to integrating ICT into the courses as being a lack of knowledge, negative attitudes, and collaboration difficulties among teachers with different views and understandings of the role of ICT (Granberg, 2005).

\section{A research study of a pilot project}

\section{The project}

The national implementation of individual development planning (IUP) in Sweden, initiated in 2006 in compulsory schooling, has influenced developments in teacher education. The Teacher Education Faculty Board at the university which is the focus of this study decided to try out digital IUP, starting with a pilot project in September 2006. The project was designed based on action research, in order to enhance the long-term development of process-based learning supported by ICT. The first action research cycle was carried out during the 20062007 academic year, and all teachers at the Faculty were invited to participate. Seven teachers volunteered, all women, from four of five Departments in the Teacher Education Faculty. Three teachers from the ICT and Learning Department, two men and one woman, worked as mentors to support didactical discussions and the use of ICT. These mentors were all familiar with digital IUP, had been active in IUP projects in compulsory schooling and had ongoing discussions with members of the Faculty Board concerning IUP in teacher education.

Supported by these mentors, the teachers designed the IUP applications to suit their courses, and these were published using one of the two digital tools offered. The first application was the existing learning management system (LMS), while the second was one already being used in some schools (Figure 1). The IUP designs varied, but they all consisted of three steps. These entailed (1) students describing their previous knowledge and creating individual goals; (2), describing their development during the course; and (3) evaluating the knowledge gained in relation to the goals. During this process, the students received supporting feedback from their teachers. This project, which aimed at trying out and implementing digital IUP in teacher education, is the subject of the current study.

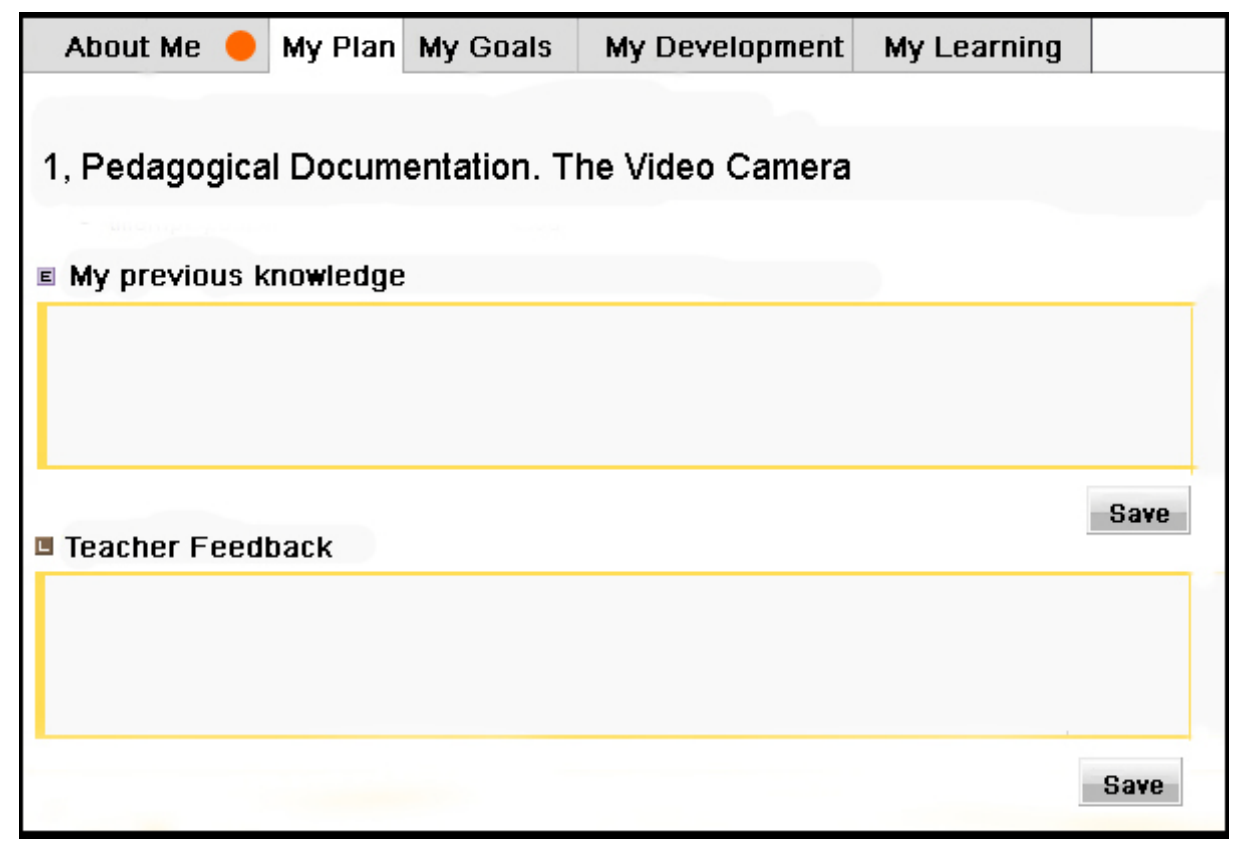

Figure 1. Screen capture from the online application, showing student and teacher contributions to be written in separate boxes. Orange dots indicate new contributions. 


\section{Aims and questions}

The study aims to illuminate these teachers' experiences as regards the pedagogical and technological benefits and obstacles of digital IUP. Furthermore, the study fosters insight into how these experiences influence decisions to use digital IUP, and offers a better understanding of the process of implementing didactic concepts supported by ICT.

The research questions arising from this study are as follows:

- How can these teachers' experiences of digital IUP be described and understood?

- How are concepts such as digital IUP and teachers' experiences of using them communicated in the context of teacher education?

- How can these teachers' roles in the process of change be described and understood?

\section{Methodology}

Pedagogical ideas and the context of teacher education cannot be considered objective concepts; rather, they are interpreted and constructed differently by individual teachers. Individual understandings of these constructs in turn influence the teachers' experiences and actions. Taking constructivism as an epistemological starting point and aiming to understand the process of change from the teacher's perspective, a hermeneutical approach is used here. Hermeneutics focuses on interpretation and understanding, and allows researchers to interpret and relate data to their own prior knowledge (Ricoeur, 1976). This process of interpretation can be described as a circle, or rather a helix, where the researcher's prior understanding is placed at its foundation and the increasing height of the helix indicates the process of developing knowledge of the subject (ibid.).

Thematic content analysis was used to structure the data, after which theory was used to establish the point of prior knowledge and map the development of further understanding in the helix of hermeneutics. A more detailed account of these theories will follow.

\section{Methods}

The teachers and mentors were invited to two semi-structured interviews. One was conducted before the project. In this interview, the informants were asked to describe themselves in relation to new pedagogical ideas, ICT, and their prior experience of process-based learning. In the second interview, conducted after the project, the informants were asked how ICT and IUP had been communicated during the process. They were also asked to reflect on their own roles in this process of change. The interviews, each lasting between 45 and 75 minutes, were recorded and transcribed.

\section{Emerging themes}

As thematic content analysis was used, the first reading aimed to form themes and find a suitable theoretical framework. Given the author's prior understanding of ICT implementation as a composite process, the teachers' experiences of complexity came out very clearly. Because the study includes a process of change, Rogers' (2003) theory of the diffusion of innovations was chosen as a theoretical starting point. Rogers defines the diffusion of an innovation, new ideas, or new technology as "the process by which an innovation is communicated through certain channels over time among the members of a social system" (ibid.:35). A more detailed description of Rogers’ theory will follow later. 
In this study, teacher education constitutes the social system in which the innovation - digital IUP - is communicated and introduced. From the second reading, the following themes were formulated:

- $\quad$ The attributes of digital IUP

- Communication of ICT and process-based learning, and

- Power relations.

The first as well as the second theme was analysed according to Rogers' theory of diffusion. In order to analyse the third theme, power relations, symbolic capital according to Bourdieu (1984) was used as analytic tool.

\section{Ethical issues}

All necessary ethical requirements of the University as outlined by the Swedish Research Council (2001) were followed. Accordingly, the aspects of beneficence, non-malfeasance, informed consent and anonymity were taken into account in planning and carrying out this study, and approval for the research design was achieved at the appropriate level of the organisation.

The author has worked as a teacher in the ICT Department since 2002, and is familiar with the context. More recently as a doctoral student, the author has been interested in questions about how the didactical use of ICT can be further developed within learning environments. Because the author's work and research occur in the same context, it is important to maintain distance from the subject of study. Therefore, the author has chosen not to take an active part in any of the courses in the project nor in the process of action research. Furthermore, it is important that the teachers who have been interviewed are aware of when and why the author is collecting information, and that these occasions are obvious to them and take place with their full permission. Between these formal data-gathering occasions, the authors' everyday contacts with colleagues will, of course, affect the understanding of the project, but these have not been documented or reproduced.

\section{Theoretical framework}

As described earlier, this study has developed three themes that emerged through an analysis of the teachers' narratives. To understand some of the interactions between these themes, arguments are drawn from the theories described below.

\section{Diffusion of innovation}

Rogers' (2003) theory, as mentioned earlier, identifies four interrelated perspectives on the process of change: the time, the innovation, the communication, and the social system.

In the time perspective, Rogers argues that, depending on the individual's 'changeability', it takes more or less time for an individual to try out and adopt or reject new ideas. Rogers defines five categories of adopters. The first two are smaller groups, namely innovators and early adopters, and are characterised as being very keen on embracing innovation. The next two categories - the early and late majorities - are more sceptical towards new ideas or technology, and will wait until an innovation has been tried out or even for management initiatives to do so before they adopt it themselves. The last category to adopt innovations, namely the laggards, will resist change for as long as possible.

When it comes to the innovation perspective, Rogers defines five innovation attributes: relative advantage, compatibility, complexity, trialability, and observability. Individuals' perceptions of these attributes may be related to their past experiences, values and needs. Rogers claims that the better the attributes of an innovation, and the more adjustable these attributes are to the context, the more readily the innovation will be adopted. 
The third perspective, communication, is important in spreading the innovation throughout an organisation. Rogers points out that one-to-one communication is more effective in raising awareness of a new idea compared to for example, use of the mass media. Furthermore, new ideas are easier to communicate and diffuse within the adoption categories rather than between them. When people share a category, they also tend to share the same understanding of concepts, values, and attitudes.

The social system, the fourth perspective, is described as a set of units that are engaged to reach a common goal. Within a social system, the decision to adopt or reject an innovation can be made at three different levels: individually, collectively, or authoritatively. Within the social system, Rogers' theory describes agents of change and opinion leaders as important to the process of change. Change agents usually try to influence members within the social system to try out and adopt new ideas that some 'change agency' has suggested. These agents may take a position between the system members and the change agency. The change agents' success is related to the time spent communicating with the system members, their ability to understand and relate to colleagues' perceptions, and the extent to which they may collaborate with opinion leaders. Being an opinion leader could be described as having an informal rather than a formal position of power. Opinion leaders are tuned into the norms of the social system and may be innovative or opponents of change, depending on prevailing circumstances. In other words, a social system may have opinion leaders that advocate change as well as those who oppose it.

Rogers' theory does not consider power relations within the social system organisation as a particular perspective of the process of diffusion. Apart from the fact that the theory discusses innovation decisions implemented by an authority, power relations are only mentioned in terms of socioeconomic status in relation to categories like opinion leaders, early adopters, etc. The perspective of power relations and social status is not emphasised at an individual level.

Researchers within the field of sociology have described a range of circumstances that influence our social positions within a social system or social field. Individual capital such as membership of groups sharing social, economic, cultural, academic, gender, and class attributes will contribute to our symbolic capital, depending on what capital is recognised as valuable within a particular social field. Depending on our individual symbolic capital, we hold different social positions within such field (Bourdieu, 1984). Symbolic capital in relation to academic capital and gender has been used to analyse the third theme - power relations.

\section{Findings}

The three themes that emerged when analysing the interviews are discussed in the following paragraphs. To recap, the themes are: the attributes of digital IUP; the communication of ICT and process-based learning; and power relations. First, however, we will characterise the teachers volunteering to join the project. Their names are fictitious.

Five of the teachers were aged 50 or older, while two were about 40 . They presented themselves as ambitious individuals who enjoyed their work and often worked after hours. Six considered themselves open to trying out new pedagogical ideas, and indicated that they were not afraid of setbacks. They could, in Rogers' terms, be described as early adopters of pedagogical ideas. These six teachers had used concepts such as learning autonomy, process writing, and portfolio in their previous teaching, and each of these women emphasised the possibility of bringing such concepts into the IUP. 
None of the seven teachers expressed any negative attitudes towards ICT. However, they approached ICT very differently. Two could be described as early adopters, searching for new ways of using ICT at work and at home. Mary said the following: "I have always loved technology, and look for ways to use ICT in my classroom." Some of the other five could be found among the early majority. Anne, for example, described herself as follows: "I am inspired by my colleagues to use the Internet in different ways, but I download and install programs unwillingly." Others, like Sarah, are in the late majority: "It is like a giant threshold every time they want me to use something new; I feel like 'Oh dear, now I have to learn something technical again'."

\section{The attributes of digital IUP}

This study considers the use of digital IUP in three courses. IUP replaced previous concepts in two of them. Course A had previously used digital process diaries; Course B had previously used a summative final written exam; while Course $C$ was being offered for the first time. The aim of using digital IUP in all courses could be described as initiating a dialogue in which students, supported by teachers, could create goals and document and reflect on their learning.

\section{Course A}

All the teachers and most of the students in this net-based in-service course had prior experience with digital process diaries. The diaries were written in MS Word and sent to digital portfolios where teachers provided feedback. In their diaries, the students wrote about how they were developing through their reading and practical work. All teachers of this course felt that process diaries and IUP were quite similar.

Two of the teachers commented that several of their students failed to use IUP as intended. Although the teachers and the students did not find the web application too complex, they definitely felt it was incompatible with adequate word processing. Julia described her observations as follows: "I see that these small boxes restrained their creativity." According to Anne, "The students are used to writing in Word, which offers large, inspiring blank pages." Sarah concluded the following: "When some of them did not write as much as intended, my feedback became occasional and very little dialogue was generated."

Two teachers initially had difficulty in finding the students' contributions. Sarah commented that "There were no dates or red flags indicating when the students wrote." Besides the dissatisfaction with the tool, the teachers pointed out the difficulties students had perceived when they were supposed to write about their learning process. Anne noted that "In the diary, the students wrote about concrete things, their work, their thoughts, what they have read ... they wrote and flourished.” The students became frustrated when they were supposed to describe their learning processes, and two of them even created their own diaries to continue applying the old process diary idea, using the old tool, MS Word.

Julia described similar difficulties among her students. Thanks to the dialogue with the teacher, however, the students overcame the obstacles: "I checked whether they had written in their IUP at least every other day, and the orange dots [showing a new contribution had been made] were really helpful." The students' and her presence in the IUP became obvious, which was important in creating dialogue.

The described obstacles can be understood from both pedagogical and technical perspectives. The students were expected to write about their knowledge development, which is far more abstract than writing about one's activities. Using Rogers' theory, this could be understood as an overrated compatibility: the pedagogical attributes of the process diaries and IUP were more unlike each other than they appeared at first, and the teachers were not fully prepared to deal with the students' frustration. 


\section{Course B}

Course B was a subject campus course in which the course goals, i.e. didactical questions, had earlier been summatively assessed through a seminar and a final written exam. IUP and formative assessment are quite different approaches.

The digital IUP supported the dialogue as intended. Hanna pointed out that "Even silent students who do not participate in dialogue in the classroom were much easier to reach. ... They have really had to think and reflect on what they have actually learned." Hanna furthermore cited the importance of using ICT to support the process: "You cannot use paper to support IUP; paper disappears and cannot change to support a process."

There were no difficulties using the web application. These students were younger (average age of 27 years compared with 42 in Group A) and were used to online chatting. They all wrote directly in the web application and in an informal style. As Hanna put it, "They used the same written language that they do in e-mail and when they chat."

The students became very active, creating their individual didactical goals. They had many ideas and planned how to practise their teaching skills. They were supported by their teachers' feedback and were offered rooms with whiteboards where they could practise. However, there was little time in the schedule for these activities, so in the end the students were unable to implement their plans. Hanna reflected on this problem as follows: "I do not know where to put the didactical stuff, to bring these questions into the course." Both the students and the teacher perceived how ICT had facilitated interaction and taking part in creative dialogue. The attributes of IUP as a pedagogical concept were, however, created during the writing process, and could not be compared with the old concept of final written exams. The IUP drew more attention to the didactical questions than the final exam did. This created problems for the teacher and the students, as limited preparations had been made for this.

\section{Course C}

This net-based course was new, and as the LMS was already familiar to the teachers and some students, they used it for the IUP and portfolio. After a running-in period, dialogue with the students started. A red flag and a date indicated new contributions, and the teachers gave feedback once a week.

Supported by the teachers' feedback, the students succeeded in creating goals and reflecting on their achievements during the course. The teachers spent considerable time making their comments useful. As Jane described it, "It is rather difficult to give encouraging feedback. It is so easy to fall into old habits and write in a way that is controlling and "finalassessment-like'. I wanted to challenge them, encourage them to take another step." Judy continued: "I can really feel that something has happened within the students, in how they have struggled and problematised themselves."

To summarise these teachers' narratives, it appeared that, depending on the teachers' and students' prior experiences of ICT and process-based assessment, the attributes of the digital IUP were perceived differently. In the groups of students in which obstacles, if any, were overcome, positive attributes like social presence (Kreijns \& Kirshner, 2001), creative writing, and ICT-supported dialogue (Dysthe, 2002) are described. Through reflective dialogue, and depending on the idea that is replaced, digital IUP will shift some focus from concrete to abstract writing, from the final product to the learning process, and from subject knowledge to teacher skills. It has been possible to try to observe these attributes, and the teachers' prior understanding of process-based assessment facilitated the experiences of compatibility and gain of digital IUP. With one exception and despite the difficulties experienced, all the teachers made individual decisions to continue using formative assessments. This is not surprising, as, in Rogers' terms, these six women are all early adopters, not afraid of setbacks, and willing to take part in the process of developing new 
ideas. Anne stated that "Nothing comes out so badly that you cannot make something good out of it.”

\section{Communication of ICT and process-based learning}

Some of these women have prior experience of working in teacher teams with colleagues who share their interest in ICT and recognise the difficulties in discussing how ICT should be integrated into courses. Similar experiences came through in the mentors' narratives. Two mentors described the miscommunications that often arose when working as a teacher in an ICT and Learning Department collaborating with teachers from other Departments. Martin described this as follows: "It is sometimes hopeless to discuss how to use ICT in our joint courses. Maybe I am not good enough at explaining the methods because they do not seem to understand." However, these obstacles between teachers and mentors had not arisen during the current project, as Susan explained: "This has been something different ... We do not talk the same language, but we share the same pedagogical idea; and based on what we have in common, we can understand each other even when it comes to ICT." The obstacles to spreading the use of new technology between Rogers' adoption categories were overcome in this case through a common interest, based on a shared pedagogical understanding.

According to Rogers' theory, it is of great importance that change agents - in this case the project participants - engage in communication with their colleagues about the new concept. However, the informants described a situation with few formal forums for pedagogical discussions. For example, the change agency here, namely the Faculty Board, had taken no action to share the participants' experiences more broadly, and Departmental management had shown little interest in their achievements. As Susan said, "There is a long tradition of final written exams and seminars; and even if there have been some initiatives aiming at other forms of assessment, these questions always seem to end up at the very bottom of the agenda."

However, portfolios and IUP have been the subject of informal conversations in smaller groups during coffee breaks and in teacher teams planning courses. Most of the seven women describe these discussions as unproductive. As Sarah put it; "It is difficult to even discuss methods like portfolios in my Department; there are colleagues who just conclude that it is too problematic, of no value ... and that is the end of the discussion." Rogers points out that personal communication between colleagues has the greatest influence on individual attitudes, and such arguments are likely to apply even when it comes to negative discussions. In the absence of formal pedagogical discussions and when conversations at a personal level tend to concern problems, the diffusion of formative assessment concepts via personal communication channels is unlikely to be very effective.

\section{Power relations}

Rogers points out the value of collaborating with opinion leaders within the social system. The context of teacher education is described as traditional - holding on to summative forms of assessing students. The established methods are valued as academically correct and will give symbolic capital to the teachers that defend the tradition. Therefore, the opinion leaders among teacher colleagues tend, in this case, to resist change and preserve the traditional norms rather than advocate change. Julia explained it as follows: "Methods like digital portfolios do not have any status; and when the issue is brought up in the coffee break, our colleagues - usually male - tend to focus on the difficulties instead of talking about the possibilities." The mentors' narratives described a similar situation, as Colin explained: "ICT has no academic value and gives low social status to those who advocate ICT-supported methods. It is regarded purely as technology. The use of ICT in academia is considered voluntary." 
Furthermore, some of these female respondent teachers described a situation in which they found themselves in an inferior position because of their gender. Susan observed as follows: "As women, we often feel we are not good enough and, therefore, are more likely to look for change." The fact that no male teachers volunteered for the project, despite half the teaching staff being men, did not surprise these women, since their experience was that men tended to keep to tradition. Sarah described the situation in the following way: "My male colleagues often turn creative discussions into something negative, in order to protect the status quo." As mentioned earlier, although these women respondents are early adopters of new pedagogical ideas, most chose to be more passive agents of change. Anne explained how she saw this: "I will continue to work with IUP and portfolios while waiting for a decision from the Faculty Board. Meanwhile, I can show others how IUP could be used to support learning, if they are interested." Judy could be described as an exception, having a position in the organisation that gives her the opportunity to discuss pedagogical methods in a formal forum. The experiences of low social position came through in some of the mentors' narratives as well. Martin described his experiences as follows: "Working in joint teacher teams, they seem to look upon me as the technical nerd - not as a teacher educator; therefore, I often keep quiet."

All but one of the ten participants thought digital IUP and/or portfolios should be used in teacher education, at least in the compulsory courses. Rogers argues that decisions to adopt new ideas in a social system can be made at different levels. These teachers as well as their mentors agreed that this had to be done via an authoritative decision. As Julia put it, "If there is any possibility of rejecting the use of IUP and portfolios, discussion among some of our colleagues will concern problems, not possibilities." However, the narratives of the three mentors showed that they did not think the management wanted to make use of their decisionmaking power. As Colin explained, "It is very clear that the management does not want to take decisions like that. They want stuff like ICT and IUP to disseminate autonomously, bottom-up." Thus, the management preferred to initiate the change, but left it to the system to make individual and collective decisions to adopt the concept.

\section{Discussion}

The participants in this project could be described as change agents advocating the concept of digital IUP initiated by the change agency, the Faculty Board. However, to communicate the experience of pedagogical attributes among colleagues outside the project group in order to disseminate the concept has been found to be difficult.

The positive attributes of digital IUP challenge the traditional way of teaching and assessing; therefore, they are not compatible with established methods being used in those contexts. Digital IUP might even appear as complex, and the relative advantages are not observable to colleagues who do not have the same degree of experience with digital processbased assessment as the project participants have. Therefore, active communication of the new concept becomes important in order to make the positive attributes observable for colleagues. However, teacher education, as a social field, values traditional ways of teaching and assessing. Therefore, a majority of the informants find themselves in a position of low symbolic capital in relation to gender and/or academic capital related to their interests in digital formative assessment. Having a situation with no formal forum, opinion leaders who defend the traditions, and a case where the majority of the participants have chosen to become passive change agents, hampers communication from taking place. The participants find themselves in a situation where the change agency relies on change agents to disseminate digital IUP from the bottom up, although a majority of the change agents have chosen to be passive: waiting for directives from the management. Under these circumstances, the majority 
of the teacher educators will, as suggested by the opinion leaders, uphold the traditional way of assessing their students.

The study has illuminated pedagogical attributes of digital IUP, and has demonstrated that, when teachers share a pedagogical vision, the difficulties of integrating ICT into courses, described by Finley and Hartman (2004) and Granberg (2005), for example, can be overcome. Furthermore, the study has highlighted the lack of formal structures for supporting pedagogical discussions and the obstacles experienced as a result by staff who are engaged in trying to support the development of ICT-supported methods of teaching and learning through informal processes of communication This understanding and experience has also highlighted the importance of not only providing challenging feedback, but also of a suitable digital tool to support dialogue. Furthermore it has also shown the need for an attitude of preparedness for change that involves an emphasis on the learning process. These are all important insights to bring to the next step of implementing digital process-based learning in teacher education. 


\section{References}

Bergström, P. \& Granberg, C. (2007). Process diaries: Formative and summative assessment in on-line courses. In Buzetto-More, N. (Ed.). Principles of effective online teaching: A handbook for educators developing e-learning. Santa Rosa. CA: Informing Science Press, pp 245-266.

Black, P. \& William, D. (1998). Inside the black box: Raising standards through classroom assessment. Phi Delta Kappa, 80(2), 139-148.

Bourdieu, P. (1984). Distinction: A social critique of the judgment of taste. Cambridge:

Harvard University Press.

Clarke, M. (2004). Reflections: Journals and reflective questions: A strategy for professional learning. Australian Journal of Teacher Education, 29(2), 1-13.

Clegg, S. \& Bradley, S. (2006). The implementation of progress files in higher education: Reflections as a national policy. Higher Education, 51, 465-486.

Conole, G. \& Dyke, M. (2004). What are the affordances of information and communication technologies? Research in Learning Technology, 12(2), 113-124.

Dysthe, O. (2002). The learning potential of a web-mediated discussion in a university course. Studies in Higher Education, 27(3), 339-352.

Dysthe, O. \& Engelsen, K. S. (2004). Portfolios and assessment in teacher education in Norway: A theory-based discussion of different models in two sites. Assessment and Evaluation in Higher Education, 29(2), 239-258.

Finley, L. \& Hartman, D. (2004). Institutional change and resistance: Teacher preparatory faculty and technology integration. Technology and Teacher Education, 12(3), 319337.

Granberg, C. (2005). ICT in teacher education - An ongoing process. Advanced Study Thesis in Professional Education, Department of Interactive Media and Learning, Umeå University, Umeå.

Hall, G. E. \& Hord, S. M. (2001). Implementing change: Patterns, principles, and potholes. Needham Heights, MA: Allyn \& Bacon.

Kirschner, P. \& Selinger, M. (2003). The state of affairs of teacher education with respect to information and communications. Technology, Pedagogy and Education, 12(1), 5-17.

Koschmann, T. (1996). Paradigm shifts and instructional technology: An introduction. In Koschmann, T. (Ed.). CSCL: Theory and practice of an emerging paradigm. Mahwah, NJ: Lawrence Erlbaum Associates, pp 1-22.

Kreijns, K., \& Kirschner, P. (2001). The social affordances of computer-supported collaborative learning environments. Paper presented at the ASEE/IEEE Frontiers in Education Conference, Reno, Nevada.

McCarney, J. (2004). Effective models of staff development in ICT. European Journal of Teacher Education, 27(1), 61-72.

QAA/Quality Assurance Agency. (2001). Guidelines for HE Progress Files. Available at http://www.qaa.ac.uk/academicinfrastructure/progressFiles/guidelines/progfile2001.pd f ; last accessed 10 June 2008.

Richardsson, J. \& Swan, K. (2003). Examining social presence in online courses in relation to students' perceived learning and satisfaction. Journal of Asynchronous Learning Network, 7(1), 68-88.

Ricoeur, P. (1976). Interpretation theory discourse and the surplus of meaning. Fort Worth, TX: Fort Worth Texas Christian University Press.

Rogers, E. (2003). Diffusion of innovations. New York: Free Press.

Scott, J. (1988). Gender and the politics of history. New York: Columbia University Press. 
Strudler, N. \& Wetzel, K. (2005). The diffusion of electronic portfolios in teacher education: Issues of initiation and implementation. Journal of Research on Teacher Education, 3(4), 411-433.

Swedish Research Council. (2001) Ethical principles of research in humanistic and social science. Available at http://www.vr.se; last accessed 10 June 2008.

The European Parliament and the Council of the European Union. (2006). Recommendation of the European Parliament and of the Council on key competences for lifelong learning. Official Journal of the European Union (2006/962/EC); available at http://eur-

lex.europa.eu/LexUriServ/site/en/oj/2006/1_394/__39420061230en00100018.pdf; last accessed 10 June 2008.

Webb, M. E. (2005). Affordances of ICT in science learning: Implications for an integrated pedagogy. International Journal of Science Education, 27(6), 705-735.

Woodward, H. \& Nanlohy, P. (2004). Digital portfolios in pre-service teacher education. Assessment in Education, 11(2), 167-178. 